\title{
A Clinico Epidemiological Study of Elderly Patients ( $\geq 60$ Years) Suffering from Presbycusis Visiting Tertiary Centre at Gorakhpur District
}

\author{
Authors \\ Mamta Kusum ${ }^{1}$, Arun Srivastava ${ }^{2}$, Arushi Sumpriya ${ }^{3}$, D K Srivastava ${ }^{4}$ \\ ${ }^{1}$ Junior Resident, Deptt. of Community Medicine, BRD Medical College, Gorakhpur, UP, India \\ ${ }^{2}$ Associate Professor, Deptt of Community Medicine, BRD Medical College, Gorakhpur, UP, India \\ ${ }^{3}$ Professor, Deptt of Community Medicine, BRD Medical College, Gorakhpur, UP, India \\ ${ }^{4}$ Assistant Professor, Deptt. of Community Medicine BRD Medical College, Gorakhpur, UP, India
}

\begin{abstract}
Objective: To study clinico-social correlates of presbycusis in elderly patients of age $\geq 60$ years.

Study Design: A cross- sectional study

Study Setting: ENT Department of B.R.D. Medical College, Gorakhpur

Study Period: October 2017 -February 2018

Result: Out of 138 patients examined for age related hearing loss $60.14 \%$ were male and $39.86 \%$ were female which shows male predominance. Most of the elderly patients belonged to $60-69$ years of age group (49.28\%), of urban area (62.32\%), Hindu (65.94\%), unemployed (89.13\%). Majority were married (72.46\%) and belonged to lower socioeconomic class (42.03\%). Majority of males (83.13\%) and females (67.27\%) having hearing loss suffered from hypertension (83.13\%). $19.27 \%$ males and $36.36 \%$ females suffering from hearing loss also suffered from diabetes mellitus. $27.27 \%$ elderly females having hearing loss had tinnitus and $45.45 \%$ had vertigo as associated symptom while only $12.05 \%$ elderly males having hearing loss were suffered from tinnitus and $27.71 \%$ males suffered from vertigo.
\end{abstract}

Keywords: Presbycusis, Elderly, vertigo, tinnitus.

\section{Introduction}

Presbycusis or age related hearing loss is the most common type of sensorineural hearing loss caused by the natural aging of the auditory system. It occurs gradually and initially affects the ability to hear higher pitched (higher frequency) sounds. Over time, it can result in individuals being unable to clearly hear sounds at progressively lower frequencies. People with presbycusis often notice that speech is loud enough, but not clear - as if the talker is mumbling.
As per WHO estimates in India there are approx 63 million people who are suffering from significant auditory impairment, this places the estimated prevalence at $6.3 \%$ in Indian population. The National Sample Survey 58th round (2002) surveyed disability in Indian household and found that hearing disability was the second most common cause of disability. In urban area loss was $9 \%$ of all disabilities and in rural area it was $10 \%{ }^{1}$

Hearing disability is an important issue in geriatric medicine because it is associated with numerous 
health issues, including accelerated cognitive decline, depression, increased risk of dementia, poorer balance, falls, hospitalizations, and early mortality. There are also social implications, such as reduced communication function, social isolation, loss of autonomy, impaired driving ability, and financial decline .This study was an attempt to know the socio-demographic and related clinical factors among elderly patients suffering from age related to hearing loss.

\section{Material and Methods}

An interview based cross sectional study was done on 138 elderly patients ( $\geq 60$ years) who came to ENT department of B.R.D. Medical College from October 2017 to February 2018. Prevalence is taken as 9\% (based on earlier study done by Varshney Saurabh et al. ${ }^{\mathbf{1}}$ A total of 153 elderly patients came for consultation for hearing loss out of which 15 refused to give consent. Therefore a total of 138 patients were enrolled for study of socio-demographic profile and clinical history. An interviewer based detailed history of sociodemographic profile questions were asked from these 138 patients. In case patients had severe hearing loss questions were asked to their attendants on taking consent. Data regarding sociodemographic profile and clinical history of elderly patients suffering from hearing loss were recoded by using predesigned and pretested questionnaire. Data collected through questionnaire was entered in the MS Excel spread sheet and analysed using SPSS and chi square test was applied to show the significance between the variables

\section{Results}

Table 1 Description of studied elderly patients according to socodemographic profile ( $\mathrm{N}=138)$

\begin{tabular}{|c|c|c|c|c|c|}
\hline Groups & Subgroups & Total $(\mathrm{N}=138)$ & Male $(n=83)$ & Female $(n=55)$ & Test of significance \\
\hline \multirow{3}{*}{ Age in years } & $60-69$ & $68(49.3 \%)$ & $33(39.76 \%)$ & $35(63.64 \%)$ & \multirow{3}{*}{$\begin{array}{c}\chi^{2}=13.75, \mathrm{p}<0.05 \\
\mathrm{df}=2\end{array}$} \\
\hline & $70-79$ & $42(30.4 \%)$ & $25(30.12 \%)$ & $17(30.9 \%)$ & \\
\hline & $>80$ & $28(20.3 \%)$ & $25(30.12 \%)$ & $3(5.45 \%)$ & \\
\hline \multirow{2}{*}{$\begin{array}{l}\text { Area } \\
\text { residence }\end{array}$} & Rural & $52(37.7 \%)$ & $30(36.14 \%)$ & $22(40 \%)$ & \multirow[t]{2}{*}{$\chi^{2}=.209, \mathrm{p}>0.05, \mathrm{df}=1$} \\
\hline & Urban & $86(62.3 \%)$ & $53(63.86 \%)$ & $33(60 \%)$ & \\
\hline \multirow[b]{2}{*}{ Religion } & Hindu & $91(65.9 \%)$ & $52(62.6 \%)$ & $39(70.9 \%)$ & \multirow[t]{2}{*}{$\chi^{2}=1.005, \mathrm{p}>0.05, \mathrm{df}=1$} \\
\hline & Muslim & $47(34.1 \%)$ & $31(37.3 \%)$ & $16(29.09 \%)$ & \\
\hline \multirow{3}{*}{ Marital status } & Married & $100(72.5 \%)$ & $69(83.1 \%)$ & $31(56.36 \%)$ & \multirow[t]{3}{*}{$\chi^{2}=12.61, p<0.05, d f=2$} \\
\hline & Unmarried & $8(5.8 \%)$ & $4(4.82 \%)$ & $4(7.27 \%)$ & \\
\hline & Widow & $30(21.7 \%)$ & $10(12.05 \%)$ & $20(36.36 \%)$ & \\
\hline \multirow{4}{*}{$\begin{array}{l}\text { Educational } \\
\text { qualification }\end{array}$} & Illiterate & $31(22.5 \%)$ & $20(24.1 \%)$ & $11(20 \%)$ & \multirow{4}{*}{$\begin{array}{c}\chi^{2}=3.91, p>0.05 \\
d f=3\end{array}$} \\
\hline & Primary & $39(28.3 \%$ & $26(31.33 \%)$ & $13(23.6 \%)$ & \\
\hline & Middle & $31(22.5 \%)$ & $14(1.87 \%)$ & $17(30.9 \%)$ & \\
\hline & Higher & $37(26.8 \%)$ & $23(27.71 \%)$ & $14(25.45 \%)$ & \\
\hline \multirow[b]{2}{*}{ Occupation } & Employed & $15(10.9 \%)$ & $13(15.66 \%)$ & $2(3.64 \%)$ & \multirow[t]{2}{*}{$\chi^{2}=4.94, p<0.05, d f=1$} \\
\hline & Unemployed & $123(89 \%)$ & $70(84.34 \%)$ & $53(96.36 \%)$ & \\
\hline \multirow{5}{*}{$\begin{array}{l}\text { Socio-economic } \\
\text { status }\end{array}$} & Class 1 & $34(24.6 \%)$ & $19(22.89 \%)$ & $15(27.27 \%)$ & \\
\hline & Class 2 & $27(19.6 \%)$ & $10(12.05 \%)$ & $17(30.9 \%)$ & \\
\hline & Class 3 & $22(15.9 \%)$ & $11(13.25 \%)$ & $11(20 \%)$ & \\
\hline & Class 4 & $26(18.8 \%)$ & $20(24.1 \%)$ & $6(10.91 \%)$ & \\
\hline & Class 5 & $32(23.2 \%)$ & $23(27.7 \%)$ & $916.36 \%)$ & \\
\hline
\end{tabular}

Table 1 shows out of 138 elderly patients of presbycusis $83(60.14 \%)$ were males and $55(39.86 \%)$ were females. 68 patients $49.28 \%$ ) were of age group 60-69 years, 42(30.43\%) were of 70-79 years and $28(20.3 \%)$ were more than 80 years. Majority of patients $(62.32 \%)$ came from urban region and $(37.68 \%)$ came from rural area.
Overall presbycusis was found more in subjects of 60-69 years of age group (49.3\%), Hindus $(65.95 \%)$, in married males $(83.13 \%)$, in unemployed $(89.13 \%)$ subjects. The distribution of hearing loss in elderly patients of different marital and employment status was compared and significant association was found. 
Table 2 Distribution of hearing loss of elderly patients as per their history of chronic illness

\begin{tabular}{|l|c|c|c|c|c|}
\hline $\begin{array}{l}\text { Chronic } \\
\text { illness }\end{array}$ & $\begin{array}{c}\text { Status of } \\
\text { patients }\end{array}$ & Male & Female & Total & Test of significance \\
\hline \multirow{3}{*}{ Hypertension } & YES & $69(83.13 \%)$ & $37(67.3 \%)$ & $106(76.8 \%)$ & $\chi^{2}=4.67$, \\
\cline { 2 - 5 } & NO & $14(16.87 \%)$ & $18(32.3 \%)$ & $32(23.2 \%)$ & $\mathrm{P}=0.03$ \\
\hline $\begin{array}{l}\text { Diabetes } \\
\text { mellitus }\end{array}$ & YES & $16(19.27 \%)$ & $20(36.4 \%)$ & $36(26.1 \%)$ & $\chi^{2}=5.01$ \\
\cline { 2 - 5 } & NO & $67(80.72 \%)$ & $35(63.6 \%)$ & $102(73.9 \%)$ & $\mathrm{P}=0.025$ \\
\hline
\end{tabular}

Table 2 shows that among studied subjects majority of males $69(83.13 \%)$ and majority of females $37(67.27 \%)$ were suffering from hypertension. Among males 16(19.27\%) were suffering with diabetes mellitus and among females $20(36.36 \%)$ were suffering with diabetes mellitus. Association of hypertension and diabetes mellitus among both male and female patients suffering from hearing loss was found to be statistically significant $(\mathrm{p}<0.05)$.

Table 3 Distribution of hearing loss in elderly patients as per their symptoms

\begin{tabular}{|l|c|c|c|c|c|}
\hline $\begin{array}{l}\text { Associated } \\
\text { symptoms }\end{array}$ & & Male & Female & Total & Test of significance \\
\hline \multirow{3}{*}{ Tinnitus } & Yes & $10(12.05 \%)$ & $15(27.27 \%)$ & $25(18.11 \%)$ & $\begin{array}{c}\chi^{2}=5.17, \mathrm{P}=0.023 \\
(\mathrm{p}<0.05)\end{array}$ \\
\cline { 2 - 5 } & No & $73(87.95 \%)$ & $40(72.72 \%)$ & $113(81.9 \%)$ & \\
\hline \multirow{3}{*}{ Vertigo } & Yes & $23(27.71 \%)$ & $25(45.45 \%)$ & $48(34.8 \%)$ & $\begin{array}{c}\chi^{2}=4.59 \\
\mathrm{P}=0.03 \\
(\mathrm{P}<0.05)\end{array}$ \\
\cline { 2 - 5 } & No & $60(72.29 \%)$ & $30(54.55 \%)$ & $90(65.2 \%)$ & $138(100 \%)$ \\
\hline
\end{tabular}

Table 3 shows that $10(12.05 \%)$ males and $15(27.27 \%)$ females were having tinnitus along with hearing loss. Proportion of female patients having tinnitus was found more than male patients. 23(27.71\%) males and 25(45.45\%) females were having vertigo along with hearing loss. Thus proportion of female patients having vertigo was also found more than male patients. Association of tinnitus and vertigo among both male and female patients with hearing loss was found to be statistically significant $(\mathrm{p}<0.05)$.

\section{Discussion}

In our study most of the patients were clustered in the age group 60-69 years. Only 28(20.29\%) patients were above 80 years. In a similar study done by Ravindra sigh Bisht et al. ${ }^{2}$ in Uttarakhand in 2016; reported the similar finding that most of the elderly patients of hearing loss were of 60 years which coincided with the demographic data and surveys were done in India, which have shown that $56 \%$ and $62 \%$ have onset of hearing loss at $\geq 60$ years of age in rural and urban backgrounds, respectively. In our study no of males having hearing loss is more than females having hearing loss. Out of 138 patients 83 $(60.14 \%)$ males and only 55(39.86\%) females had hearing loss. In a study done by Manish Sharma et $a l^{3}$ male: female sex ratio was found 1.35:1 .

Another study done in India by Trilok C Guleria et $a l^{4}$ in Shimla Himanchal Pradesh hearing loss was more common in elderly males than females.Similar findings were reported by Hannula $S$. et al in Northen Finland in which $36.8 \%$ elderly men and $18.4 \%$ elderly women were suffering from hearing loss.

In our study majority of patients were Hindu i.e. out of 138 patients $91(65.94 \%)$ were Hindu and 47(34.06\%) were Muslims. This might be due to high population of Hindus in this region. Rest other religions are not seen in the study. Similar was also found by Ravindra singh Bisht ${ }^{2}$ in his study in Uttarakhand where Hindus contributed 95.6\% and Muslims only $4.4 \%$.

In this study $123(89.13 \%)$ patients were unemployed and 15(10.87\%) were employed .In a study done by Susan et $a l^{5}$ it was found that hearing loss was the only factor that was 
independently associated with all three measures of socioeconomic status: low educational attainment, low income, and unemployment/ underemployment.

In our study; it was observed that more no. of male patients $69(88.13 \%$ ) (with hypertension) had hearing loss than female patients $37(67.27 \%)$ (having hypertension). More no. of females (36.4\%) suffering from Diabetes mellitus showed hearing loss than males $(19.27 \%)$ suffering from diabetes mellitus.

Similar results were found in a study done by In Hwan $O h^{6}$ in which The prevalence rates of hearing loss were significantly greater in subjects with than without hypertension (10.9\% vs. $6.6 \%$, $\mathrm{p}<0.05)$ and in subjects with than without DM $(17.3 \%$ vs. $6.5 \%, \mathrm{p}<0.05)$. DM and hypertension, which are common degenerative diseases frequently accompanying aging, have been reported to be closely related to aging-related hearing loss. ${ }^{7,8}$ In our study it was observed that vertigo was more common in elderly females $(27.27 \%)$ than males(12.05\%). Tinnitus was observed more in elderly females $(45.45 \%)$ than males $(27.71 \%)$.

In a study done by $L C$ Carmo $^{9}$ in 2008 the incidence of tinnitus $(64.4 \%$ and $72.5 \%$, for men and women, respectively. They stated that such difference may be associated with the fact that they included in their study only elderly with one or more hearing complaints. About dizziness, there was a relationship with gender $(p<0.05)$ being more common in the elderly women (20.0\%). In their investigation done by Kamierczak \& Doroszewska ${ }^{10}$ it was concluded that despite not finding any difference in the distribution of dizziness between elderly men and women, vertigo was more frequent in women.

\section{Conclusion and Recommendations}

In our study incident of hearing loss was more in elderly males than elderly females. A majority of patients lie in the age group 60-69 years $(68 ; 49.28 \%)$. There was a higher percentage of presbycusis reported among urban, married, unemployed Hindu male. Public should be educated about the problems elderly persons face due to their hearing loss and the persons having hearing loss him/herself should have knowledge how to cope with the problem. They should talk about their difficulty with their family and friends. Elderly persons should be counseled so that they can tell their friends and family about their hearing loss. An elderly person having hearing loss must 1) speak face to face so that you can see the faces. Watch face movement and see the expressions, it may help to understand better.2) Ask people to speak louder, but not shout. Tell them they do not have to talk slowly, just more clearly. 3)Turn off the TV or the radio if you aren't actively listening to it. 4)When you go to a restaurant, do not sit near the kitchen or near a band playing music. Background noise makes it hard to hear people talk. 5)Aware of your need for proper posture while doing your routine work if you are suffering from vertigo and tinnitus.

\section{References}

1. Varshney saurabh ,Deafness in India Published in "INDIAN JOURNAL OF OTOLOGY" Vol 22, issue 2 ,p.73-76

2. Bisht RS, Sikarwar V. Mina R, Arya A,An epidemiological study on hearing loss and its demographic charaterstics within Garhwal region of Utterakhand, Indian journal of otology,2016,Vol.22,Issue 2, pg105-109,

3. Jamwal P, Kishore K, Sharma Manish, Goel Mohit, Pattern of Sensorineural Hearing Loss In Patients Attending ENT OPD J K SCIENCE, Vol. 19 No. 1, Jan.March 2017

4. Trilok C. Guleria1*, Shobha Mohindroo2, Narender K. Mohindroo1 , Ramesh K. Azad; Prevalence and etiology of hearing impairment in urban area of Shimla, Himachal Pradesh, India: a cross sectional observational study; International Journal of Research in Medical Sciences Guleria 
TC et al. Int J Res Med Sci. 2017 Apr;5(4):1252-125

5. Susan D. Emmett, MD1,2 and Howard W. Francis, MD, MBA1 The Socioeconomic Impact of Hearing Loss in US Adults Published in final edited form as: Otol Neurotol. 2015 March ; 36(3): 545-550.

6. In-Hwan Oh,\# 1 Jong Hoon Lee,\# 2 Dong Choon Park, 3 MyungGu Kim, 4 Ji Hyun Chung, 5Sang Hoon Kim, 5 and Seung Geun Yeo 5Hearing Loss as a Function of Aging and Diabetes Mellitus: A Cross Sectional StudyPLoS One. 2014; 9(12): e116161.Published online 2014 Dec 30. doi: 10.1371/journal.pone.0116161

7. World Health Organization A global brief on hypertension. Silent killer, global public health crisis: World Health Day, vol. 1 (2013), pp. 1-40

8. NCD Risk Factor Collaboration (NCDRisC)Worldwide trends in diabetes since 1980: a pooled analysis of 751 populationbased studies with 4.4 million participants Lancet, 387 (2016), pp. 1513-1530

9. LC Carmo, Audiological study of an elderly brazilian population - SciELO, 2008 www.scielo.br/pdf/rboto/v74n3/en_06.pdf.

10. Kazmierczak H, Doroszewska G. Metabolic disorders in vertigo, tinnitus, and hearing loss. Int Tinnitus J 2001;7(1): 54-8. 